\title{
PERCEPÇÃO DE RISCO VERSUS PERIGO REAL: UM ESTUDO DE CASO SOBRE RESÍDUOS DOS SERVIÇOS DE SAÚDE
}

\section{PERCEPTION OF RISK VERSUS REAL DANGER: A CASE STUDY ON WASTE HEALTH SERVICES}

\author{
Ezequiel Vieira dos Santos \\ Programa Pós-Graduação Análise Ambiental Integrada \\ Universidade Federal de São Paulo (UNIFESP), Diadema, Brasil \\ evieiradossantos@gmail.com \\ Luciana Aparecida Farias \\ Programa Pós-Graduação Análise Ambiental Integrada \\ Universidade Federal de São Paulo (UNIFESP), Diadema, Brasil \\ luciana.farias@unifesp.br \\ Giovano Candiani \\ Programa Pós-Graduação Análise Ambiental Integrada \\ Universidade Federal de São Paulo (UNIFESP), Diadema, Brasil \\ gcandiani@unifesp.br
}

\begin{abstract}
RESUMO
O presente trabalho teve como objetivo avaliar a percepção de risco de trabalhadores que realizavam o manuseio de Resíduos dos Serviços de Saúde (RSS) de uma unidade hospitalar na região metropolitana de São Paulo. Buscando responder as seguintes questões de investigação: 1) seria a falta de conhecimento em relação ao perigo que os RSS apresentam a responsável pela menor percepção de risco, assim favorecendo a ocorrência de acidentes? e 2) ou por outro lado, seria a estrutura organizacional de controle e descarte deste material a responsável pela imprudência e a destinação incorreta? Esta pesquisa teve caráter qualitativo, na forma de um estudo de caso, sendo que foi utilizado um questionário estruturado e a observação participante como estratégia para coleta de dados. A pesquisa foi submetida ao Comitê de Ética (CAAE 05572818.0.0000.5505/parecer n. 3318.211). Os resultados obtidos evidenciaram que a variável conhecimento teve menor impacto na percepção de risco e o que mais expunha os trabalhadores ao perigo era a infraestrutura. Portanto, concluiu-se que mesmo os trabalhadores tendo uma percepção de risco relativamente próxima ao perigo real, estes estavam sujeitos a acidentes e contaminações devido à infraestrutura disponibilizada pela organização.
\end{abstract}

Palavras-chave: Percepção. Resíduos de Serviços de Saúde. Meio Ambiente.

\begin{abstract}
This study aimed to assess the risk perception of workers who performed the handling of medical waste of a hospital in the metropolitan region of São Paulo. The research questions for this study were: 1) would it be the lack of knowledge in relation to the danger that the medical waste presents responsible for the lower perception of risk, thus favoring the occurrence of accidents?; or 2) Would it be the organizational structure of control and disposal of this material the responsible for imprudence and incorrect destination? The study was qualitative as a case study. For data collection, a structured questionnaire was applied, and a Participant Observation was carried out. The research was submitted to the Ethics Committee (CAAE 05572818.0.0000.5505/decision n. 3318.211). The results obtained showed that the knowledge variable had less impact on the perception of risk and that it was the infrastructure that exposed workers to a greater danger of accidents. Therefore, it was concluded that even the workers having a perception of risk relatively close to the real
\end{abstract}

Recebido em: 18/12/2020

Aceito para publicação em: 03/04/2021. 
danger, they were subject to accidents and contamination due to the infrastructure provided by the organization.

Keywords: Perception. Healthcare waste. Environment.

\section{INTRODUÇÃO}

A partir do momento que se utiliza algum bem de consumo, alimentação, higiene ou até mesmo recursos de assistência à saúde, temos a transformação destes materiais, gerando resíduos dos quais muitos não são mais passíveis de utilização, recebendo a denominação de rejeitos (Brasil, 2010).

O diagnóstico da geração de Resíduos Sólidos Urbanos (RSU) no Brasil revelou que em todo o país, estima-se que foram coletadas 62,78 milhões de toneladas por ano ou 172,0 mil toneladas por dia de RSU nos municípios brasileiros, no ano de 2018 (Brasil, 2019). Levando a crescente geração de Resíduos Sólidos (RS) a serem objeto de investigação de inúmeros estudos (Marchi, 2015; Silva, et al., 2017; Schueler, et al., 2018; Klein, et al., 2018; Vieira, et al., 2019; Ito, 2019).

De uma maneira geral, os RS podem ser definidos como materiais e objetos descartados, resultado das mais diversas atividades humanas na sociedade, podendo estar nos estados sólido, gasoso e líquido e cujas particularidades tornem inviável o seu lançamento na rede pública de esgotos (Brasil, 2010). Dentro dessa variedade, um tipo de resíduo que se destaca pela sua periculosidade é o Resíduo de Serviços de Saúde (RSS). Este recebendo, inclusive, legislação e classificação específicas, bem como atenção especial até o descarte final adequado, devido aos graves problemas que podem oferecer por apresentarem componentes de natureza química, biológica ou radioativa potencialmente perigosos e que se descartados de forma incorreta podem acarretar inclusive em crimes ambientais (Brasil, 1998; Brasil, 2004, Conama, 2005). E mesmo sendo produzidos em menor volume se comparados ao RS, segundo Ramos et al., (2011), os RSS compõem parte importante do total dos RSU não pela quantidade gerada, mas pelo potencial perigo que oferece à saúde ambiental e coletiva.

De acordo com um estudo feito pelo Hospital Albert Einstein, o maior risco ambiental dos RSS é representado pelo chamado "lixo infectante". Caracterizando-se pela presença de agentes biológicos como sangue e derivados, secreções e excreções humanas, tecidos, partes de órgãos, peças anatômicas; além de resíduos de laboratórios de análises e de microbiologia, de áreas de isolamento, de terapias intensivas, de unidades de internação, assim como materiais perfurocortantes (Alencar, 2017). Dessa forma, pode-se inferir que há a necessidade de um gerenciamento adequado desse material, de maneira a evitar não somente elevados índices de infecção hospitalar, mas também a geração de epidemias ou mesmo endemias devido a contaminações do lençol freático (Portella \& Ribeiro, 2014). Portanto, devido ao elevado perigo que apresentam, o tema RSS têm favorecido o surgimento de pesquisas que tratam e refletem sobre essa problemática (Ferrareze et. al. 2007; Zamoner, 2008;

Neste sentido uma questão se apresenta: no gerenciamento adequado de RSS, quais são os aspectos importantes que devem ser considerados? Para Gonçalves, et al., (2011), por exemplo, uma gestão adequada desse material deve ser um processo contínuo, dependente de atualizações técnico-científicas, cumprimento das normas regulamentadoras e legislações vigentes e, particularmente da qualificação dos recursos humanos. Já para outros autores é importante também entender a relação existente entre a subjetividade dos indivíduos envolvidos no manejo e gerenciamento dos RSS e a melhoria da qualidade do processo no trabalho com os RSS, o que envolveria a implementação de práticas corretas, seguras e preventivas. Neste contexto, vem se destacando a importância dos estudos de Percepção de Risco no gerenciamento adequado desse tipo de resíduo (Navarro, 2010; Pereira, 2011; Rodrigues, et. al., 2016; Camargo \& Melo, 2017; Barros, et al., 2020).

Contudo, uma clara conceituação de termos se faz necessária. Risco e perigo, por exemplo, muitas vezes são utilizados como sinônimos no senso comum, mas trazem significados diferentes, ou até mesmo sentidos diferentes quando falamos de percepção de risco (Kolluru, 1996). O que nos leva à 
necessidade de entender o que é percepção e como essa compreensão se materializa em estudos de percepção de risco.

\section{Percepção e Percepção de Risco versus Perigo Real}

Uma busca ativa a respeito do sentido da palavra "percepção" nos leva à mais de uma possibilidade do que seria 0 ato de perceber. No dicionário Houaiss (2002), por exemplo o termo percepção teria origem etimológica no latim perceptione, que significa compreensão, faculdade de perceber, ver a "realidade" por meio da apreensão dos sentidos ou da mente. A consciência dos elementos da "realidade" por meio das sensações físicas. Já no dicionário digital Aulete (2020) o termo percepção além de captar a "realidade" por meio das sensações, também traria o sentido de uma ação de analisar, diagnosticar, avaliar, o que necessariamente levaria à necessidade de adoção de critérios, os quais podem variar de um indivíduo para o outro, de uma cultura para outra. Ou seja, neste sentido o ato de perceber iria muito além de somente captar a "realidade" por meio dos nossos sentidos.

Para as neurociências, por exemplo, a percepção refere-se à capacidade, nos seres humanos, de associar as informações sensoriais à memória e à cognição, de modo a formar uma representação e por sua vez, um conceito sobre a "realidade" e sobre nós mesmos, orientando nosso comportamento (Lent, 2010). Dessa forma, a percepção é dependente dos sentidos, mas diferente deles, o que a torna uma experiência mental particular.

Essa questão é fundamental quando comparamos, por exemplo, percepção de risco versus perigo real, pois no cotidiano de nossas experiências, de um modo geral, utilizamos a percepção para justificar nossas crenças e decisões (Smith, 2014). Enquanto perigo pode ser considerado uma condição ou um conjunto de circunstâncias que têm o real potencial de causar ou contribuir para uma lesão ou morte segundo Sanders \& McCormick (1993). Risco, por sua vez, fala de probabilidades e incertezas, além de depender de como percebemos e avaliamos o perigo que se apresenta. Segundo Lola Lopes (1987, cit. por Lima, 2003), a palavra "risco" refere-se a situações em que se toma uma decisão cujas consequências dependem do resultado de acontecimentos futuros que têm probabilidades conhecidas de ocorrerem.

O risco pode então ter vários sentidos e conforme cada indivíduo atribui um sentido diferente para o risco, a sua percepção pode ser afetada. Portanto, reunindo os conceitos de percepção e de risco, para fins deste trabalho, entende-se por percepção de risco, o processo de organizar e interpretar os dados sensoriais diante de um possível evento perigoso, imprevisto ou provável, o qual pode ocasionar danos à saúde, ao meio ambiente e à sociedade (Poffo, 2011).

Essas reflexões acerca das incertezas, perigos e riscos quando contextualizados na área de saúde, por exemplo, podem subsidiar estratégias que objetivem estabelecer prioridades de políticas institucionais, particularmente no tocando aos RSS.

Slovic (1987) reflete sobre isso em seu trabalho Perception of risk, um dos artigos mais citados e antigos na literatura sobre o tema, declarando que enquanto analistas empregam técnicas sofisticadas para avaliar riscos, a maioria dos cidadãos tem julgamento intuitivo sobre o risco normalmente chamado de "percepção de risco". E segundo Bley $(2007$, p.113) "a percepção de risco diz respeito à capacidade da pessoa de identificar os perigos e reconhecer os riscos, atribuindo-Ihe significado, seja no trabalho, no trânsito, no ar" [...]. Sendo a capacidade de percepção de risco dos indivíduos influenciada por inúmeros fatores, entre eles o estado de saúde, da atenção, do estado emocional, entre outros, inclusive culturais e sociais.

Dentro dessa perspectiva, o presente trabalho teve como objetivo avaliar a percepção de risco de trabalhadores que realizavam o manuseio de RSS de uma unidade hospitalar que atende as especialidades de maternidade e emergencial na região metropolitana de São Paulo. Buscando responder as seguintes questões de investigação: 1) seria a falta de conhecimento em relação ao perigo que os RSS apresentam a responsável pela menor percepção de risco, assim favorecendo a ocorrência de acidentes? e 2) ou por outro lado, seria a estrutura organizacional de controle e descarte deste material a responsável pela imprudência e a destinação incorreta?

Para Lin e Mills (2001), os principais fatores que influenciam a segurança são o desempenho da organização, o tamanho da companhia, a infraestrutura, a gestão e o compromisso dos funcionários quanto à saúde e segurança do trabalho. Por outro lado, tanto a literatura nacional, quanto a internacional, vem destacando também que a variável "conhecimento" é um componente importante dessa equação (Ferreira \& Teixeira, 2010; Pereira, 2011; Silva e col. 2012; Karki e col., 2020). 
Portanto, assumindo que fatores individuais, socioculturais e estruturais influenciam direta e indiretamente as percepções de risco que os indivíduos têm sobre diferentes perigos, estudos que ajudem a elucidar quais são os interesses, os valores e os possíveis pontos de conflitos existentes nesta questão, podem ajudar os tomadores de decisão a aperfeiçoar processos decisórios que reduzam acidentes e minimizem/eliminem possíveis impactos ambientais, bem como melhore a comunicação de risco aos trabalhadores.

\section{METODOLOGIA}

Esta pesquisa teve caráter qualitativo, na forma de um estudo de caso. Sendo que a pesquisa qualitativa tem sido constantemente referida nos estudos com foco para a compreensão da vida humana, nos campos como sociologia, antropologia, psicologia, dentre outros campos das ciências sociais (Denzin \& Lincoln, 2000; Creswell, 2010). A pesquisa foi submetida e aprovada pelo Comitê de Ética (CAAE 05572818.0.0000.5505/parecer n. 3318.211).

\section{Do local da Pesquisa}

Criada na década de 1980, a unidade escolhida, que agora será identifica de HP, está localizada na região metropolitana de São Paulo e suas especialidades compreendem atendimentos hospitalares emergenciais e obstetrícia, além de cirurgias de pequenos portes (consideradas minimamente invasivas, que significa que não há a necessidade de longos períodos de internação para realização e recuperação).

Foi realizado um levantamento para entender quais tipos de resíduos eram aplicáveis à unidade hospitalar HP, sendo encontrado: resíduos - Grupo A: com a possível presença de agentes biológicos; Grupo B: contendo substâncias químicas que podem apresentar risco à saúde ou ao meio ambiente; Grupo C: provenientes de descartes de material radioativo; resíduos - Grupo D: que não apresentavam risco biológico, químico ou radiológico à saúde ou ao meio ambiente, podendo ser equiparados aos resíduos domiciliares; resíduos - Grupo E: materiais perfuro cortantes ou escarificantes.

Os RSS eram gerenciados de acordo com o PGRSS da organização e esta documentação era composta por uma estrutura de: Manual (PGRSS): orientador de toda a estrutura de gerenciamento de resíduos sólidos da saúde da organização e todas as referências documentais utilizadas; Protocolos: documentos disponibilizados para a área operacional onde detalha a execução de cada atividade e; fluxogramas: Ilustrações que mostram todo o caminho de execução das atividades de forma mais representativa.

Os resíduos descartados pelas áreas eram armazenados em recipientes disponibilizados nos próprios postos de trabalhos, tendo recipientes específicos como de perfurocortantes e de coleta seletiva, de resíduos orgânicos, por exemplo. Sendo posteriormente coletados em dois momentos, o primeiro quando o responsável da área identificava que a quantidade de resíduos excedeu o limite máximo permitido, neste caso ele acionava a área de gerenciamento que realizava a coleta e disponibilizava um novo recipiente. E o outro momento no horário pré-definido pela área responsável, no qual um funcionário da equipe transitava pelas áreas do hospital realizando a coleta dos resíduos descartados, indiferente da quantidade de resíduos descartados.

Após esta coleta das áreas, estes resíduos eram transportados até a área de armazenamento de resíduos da unidade que fica do lado externo da unidade. Periodicamente (a cada 2 dias) uma empresa terceira era responsável em ir até a unidade e realizar a coleta dos resíduos para a destinação final.

Existiam também protocolos para emergências como derramamento de resíduos ou acidente com os trabalhadores.

\section{População do Estudo}

Para se entender a operacionalização da área responsável pelo gerenciamento dos RSS da HP, foi realizado um mapeamento considerando e separando a estrutura de acordo com o nível de hierarquia aplicado pela organização. Ficou nítido que na estrutura aplicada existia a separação de níveis operacionais, que eram os executantes no manuseio dos resíduos nos estágios do processo de gerenciamento e os de gestão, que eram responsáveis por estabelecer e controlar os processos, além de fornecer os subsídios necessários para sua execução, conforme será detalhado na Tabela 1 do item resultados. 
Para fins de estudo desta pesquisa, o questionário foi aplicado a todos os 12 funcionários da unidade hospitalar que compunham a estrutura da área de manuseio e gerenciamento de resíduos, sendo que, oito eram operacionais. Todos assinaram o Termo de Livre Consentimento, concordando participar da pesquisa.

\section{Do Instrumento e da Coleta de Dados}

No presente trabalho foi adotada a observação participante com objetivo de avaliar o processo de gerenciamento dos RSS, com anotação em diário de campo do que foi observado e a aplicação de um questionário estruturado com a adoção da escala Likert para a avaliação da percepção de risco.

A observação participante foi realizada entre os dias 01/10/2019 à 09/10/2019, sendo que o período de permanência no local para observação das atividades e dos locais (infraestrutura) do hospital HP, se deu em período integral, para que assim, pudesse ser avaliado também, a utilização da infraestrutura entre os turnos de trabalho dos trabalhadores que manuseiam os RSS. Além deste ponto, aliada a entrevista de percepção de risco e avaliação do local, foi também realizado o acompanhamento da atividade a nível de fluxo do processo, ou seja, acompanhando toda a cadeia de geração, manuseio e transporte dos RSS entre os níveis estabelecidos pelo hospital HP.

O questionário foi estruturado de forma a permitir a avaliação do quanto a variável conhecimento estaria influenciando ou não na percepção de risco dos trabalhadores em relação a um perigo real (que no presente caso estaria relacionado principalmente à infraestrutura oferecida pela instituição, conforme questão de investigação dois). Para tanto, o mesmo foi dividido em seis blocos: Bloco A Características/perfil dos entrevistados. Bloco B - Conhecimento e percepção de risco - questões relacionadas ao grau de conhecimento sobre RSS e a percepção de risco em relação a eles. Bloco $C$ - Perigo e percepção de risco - questões que buscavam avaliar quais os perigos a que os trabalhadores estavam expostos e a percepção de risco em relação ao uso de EPI's. Bloco D Gerenciamento e percepção de risco - avaliação do processo de gerenciamento do hospital e a sua relação com a percepção de risco. Bloco E - Protocolos e percepção de risco - avaliação do conhecimento, entendimento e aplicação dos protocolos existentes para o gerenciamento de resíduos do hospital. Bloco F - Ambiente e percepção de risco - avaliação do perigo associado ao meio ambiente devido a exposição aos RSS, a forma de gerenciamento em função das necessidades ambientais existentes, bem como a percepção de risco em relação a esse processo.

Segundo alguns autores (Schein, 1992) os influenciadores da cultura organizacional são os fundadores e as principais lideranças da empresa. Como definidores do modelo de gestão por deterem o poder máximo na empresa, impõem suas convicções pessoais, o seu jeito próprio de fazer as coisas acontecerem. Por tais motivos, não houve distinção, com perguntas diferenciadas ou específicas, entre os questionários aplicados ao nível de gestão e operacional com o propósito de entender o comportamento entre os níveis, uma vez que a operação possui uma gerência com hierarquias previamente estabelecidas, poderiam ser estabelecidos protocolos onde, ao nível de gestão, poderiam atender às necessidades de manuseio, porém não refletindo a realidade operacional.

\section{Da Análise dos Resultados}

Os resultados foram descritos em tabelas para fins de organização e para as questões abertas foi realizada uma análise de conteúdo adaptada, segundo o que preconiza Bardin, 2011. Foi realizada uma pré-análise onde se fez uma leitura exaustiva do material, buscando uma possível similitude nas respostas referente à pertinência que refere-se a coerência com o proposto no estudo. A segunda fase foi a exploratória, onde o material adquirido do texto dos participantes foi categorizado de acordo com o tema e abordagem onde foram destacadas palavras chaves afim de se obter um sentido à fala, bem como respostas que os participantes derem à algumas das questões. Já na última etapa se fez o tratamento dos resultados, inferência e interpretação, tem o objetivo de apreender os conteúdos de todo o material coletado. 


\section{RESULTADOS E DISCUSSÃO}

\section{Resultados}

\section{Dos Participantes}

Do total de 12 profissionais, nove foram do gênero masculino e três do gênero feminino, sendo que a faixa etária dos profissionais se estabeleceu conforme segue: quatro funcionários tinham de 25 a 28 anos; três funcionários tinham de 29 a 32 anos; um funcionário tinha entre 33 a 36 anos; quatro funcionários tinham de 37 a 40 anos.

Já em relação ao nível de escolaridade, três (25\%) tinham o superior completo; sete (58\%) tinham o ensino médio completo e dois (17\%) tinham o nível técnico.

Não houve nenhum funcionário entrevistado que não tivesse ao menos o ensino fundamental, pois a área é estruturada de modo que os funcionários possuam o mínimo de compreensão das diretrizes para manuseio dos RSS, bem como o preenchimento correto dos formulários aplicáveis.

Também foi identificado na observação participante que existiam três estágios de contato entre os trabalhadores que manuseavam diretamente os RSS: ESTÁGIO DE COLETA 1 - retirada da fonte geradora do resíduo e envio para ponto de armazenamento. É onde se tem o contato direto com o resíduo. ESTÁGIO DE COLETA 2 - retirada do ponto de armazenamento 1 e transporte para container de retirada externa, estágio considerado como perigo médio, pois não há o contato direto com os resíduos uma vez que eles já estão em recipientes específicos. ESTÁGIO DE COLETA 3 retirada da organização e transporte para descarte final, considerado como baixo perigo, pois não há nenhum contato direto.

Tabela 1 - Estrutura da área de gerenciamento de resíduos

\begin{tabular}{|c|c|l|c|}
\hline CARGO & $\begin{array}{c}\text { SIGLA } \\
\text { CARGO }\end{array}$ & \multicolumn{1}{c|}{ RESPONSABILIDADES } & TURNO \\
\hline Gerente & Gr. & $\begin{array}{l}\text { Estruturar o gerenciamento de resíduos sólidos da } \\
\text { unidade. }\end{array}$ & Integral \\
Analistas & Ana. & $\begin{array}{l}\text { Distribuição das demandas da área; Criação do roteiro } \\
\text { de execução das tarefas; Monitoramento dos } \\
\text { indicadores relacionados. } \\
\text { Controle operacional do gerenciamento de resíduos da } \\
\text { unidade; estabelecer o plano de coleta dos resíduos; } \\
\text { monitorar a geração e o descarte correto. }\end{array}$ & Integral \\
Auxiliares & Aux. & $\begin{array}{l}\text { Coleta dos resíduos estágio 1 e 2; transportar os } \\
\text { resíduos até o ponto de armazenamento da unidade. }\end{array}$ & $\begin{array}{c}1^{\circ} \text { e 20 } \\
\text { turno }\end{array}$ \\
\hline
\end{tabular}

Fonte: Elaborado pelo autor.

Para se avaliar a variável conhecimento no que diz respeito à manipulação de RSS, buscou-se obter dados/informações que atestassem o nível de conhecimento dos trabalhadores em função dos perigos apresentados e os riscos que estes perigos poderiam gerar (Tabela 2).

De forma geral, os trabalhadores demonstraram conhecimento mínimo quanto as implicações geradas no manuseio dos RSS, compreendiam a importância do manuseio correto e como descartar este material de acordo com o estágio de aplicação. Contudo, um fator de atenção é que, mesmo respondendo o que são RSS, não foram obtidos exemplos detalhados de tais resíduos, indiferente do cargo ou nível hierárquico na área, o que pode indicar graus de desconhecimento em alguma etapa da gestão do RSS. Resultados parecidos foram obtidos em outros estudos, nos quais a análise das respostas pressupõe que alguns dos profissionais entrevistados tinham um conhecimento parcial em algumas das etapas de gestão dos RSS (Mendes, 2005; Pereira, 2011; Stehling et al., 
2013). O que pode impactar na percepção de risco pelo distanciamento da percepção em relação ao perigo real, bem como no correto manuseio dos RSS.

Dos participantes, $92 \%$ responderam que tinham consciência do perigo que estavam expostos ao manusear RSS e 58\% responderam que conseguiam identificar um RSS durante o manuseio, além de terem consciência que os RSS podem trazer sérias complicações à saúde.

Do total de participantes, $33 \%$ que responderam que consideram extremamente perigoso o manuseio de RSS, referindo-se aos trabalhadores que executavam o ESTÁGIO DE COLETA 1, no qual é retirada a fonte geradora do resíduo e enviado para ponto de armazenamento no ESTÁGIO 2, portanto é o local onde se tem o contato direto com os RSS.

Tabela 2 - Respostas dos participantes referentes ao Bloco B - variável de conhecimento e percepção de risco

\begin{tabular}{|c|c|c|}
\hline PERGUNTA & RESPOSTAS & CATEGORIA \\
\hline $\begin{array}{l}\text { Descreva com } \\
\text { suas palavras o } \\
\text { que são resíduos } \\
\text { sólidos da saúde }\end{array}$ & $\begin{array}{l}\text { Sobra de procedimentos (Aux.); } \\
\text { O que não serve mais para utilizar (Aux.); } \\
\text { Sobra, o que não se utiliza mais nos procedimentos } \\
\text { (Aux.); } \\
\text { Restos de insumos utilizados nos procedimentos } \\
\text { (Aux.); } \\
\text { Resíduos que sobram dos procedimentos (Ana.); } \\
\text { Materiais utilizados nos procedimentos (Coord.); } \\
\text { Resíduos gerados de procedimentos hospitalares que } \\
\text { possuem potencial risco de contaminação (Gr.); }\end{array}$ & $\begin{array}{l}\text { Resíduos/sobras de } \\
\text { procedimentos }\end{array}$ \\
\hline $\begin{array}{l}\text { Já trabalhou com } \\
\text { Resíduos } \\
\text { Sólidos? Se sim, } \\
\text { quais: }\end{array}$ & $\begin{array}{l}\text { Somente na unidade (Gr., Coord., Aux.); } \\
\text { Embalagens diversas (Aux.); } \\
\text { Não (Aux.); } \\
\text { 1ํemprego com resíduos (Ana.); }\end{array}$ & Embalagens \\
\hline $\begin{array}{l}\text { Qual a sua } \\
\text { percepção em } \\
\text { executar uma } \\
\text { tarefa que } \\
\text { manuseia } \\
\text { resíduos } \\
\text { oriundos de } \\
\text { procedimentos } \\
\text { médicos? }\end{array}$ & $\begin{array}{l}\text { Perigoso, mas se considera bem protegido (Aux.); } \\
\text { Preocupada, pode se contaminar com facilidade } \\
\text { (Aux.); } \\
\text { Perigoso; Estou em risco constante (Aux.); } \\
\text { Fico preocupado, posso me contaminar (Aux.); } \\
\text { Atenção, pois são materiais potencialmente } \\
\text { infectantes (Ana., Coord.); } \\
\text { Atenção, pois oferecem riscos graves (Gr.); } \\
\text { Em estado de alerta em função dos riscos (Coord.); }\end{array}$ & $\begin{array}{l}\text { Preocupação com o perigo/risco } \\
\text { de contaminação }\end{array}$ \\
\hline $\begin{array}{l}\text { Na sua } \\
\text { percepção, quais } \\
\text { tipos de riscos } \\
\text { você está } \\
\text { exposto ao } \\
\text { manusear estes } \\
\text { resíduos? }\end{array}$ & $\begin{array}{l}\text { Doenças na pele e no sangue (Aux.); } \\
\text { Ferimentos e contrair doenças (Aux.); } \\
\text { Doenças e ferimentos (Aux.); } \\
\quad \text { Cortes, furos e contaminações (Aux.); } \\
\text { Infecções, ferimentos e doenças contagiosas (Ana.); } \\
\text { Doenças, contaminações, ferimentos graves (Coord.); } \\
\text { Contrair doenças e infecções hospitalares (Gr.); }\end{array}$ & Contrair doenças e ferimentos \\
\hline
\end{tabular}

Fonte: Elaborado pelo autor. 
O grupo de questões do Bloco $\mathrm{C}$ buscou avaliar como os participantes percebiam a execução de suas atividades, incluindo a utilização ou não de EPI'S. Entre os participantes, houve uma diferenciação na descrição dos EPI's utilizados, variando de acordo com o estágio de operação dos trabalhadores e, uma relação entre o tempo de serviço e o entendimento da importância do uso de EPI. Os trabalhadores que atuavam a menos tempo na unidade estavam mais conscientes neste aspecto, enquanto colaboradores com mais tempo de serviço apresentaram maior dificuldade em responder sobre este item e também quanto ao uso dos EPI'S. À medida que o tempo na organização aumenta, parece haver uma tendência de os trabalhadores considerarem "menos crítica" a utilização de tais EPI's.

Neste sentido, Bley (2007, p. 113) especifica que:

A percepção de risco diz respeito à capacidade da pessoa de identificar os perigos e reconhecer os riscos atribuindo-Ihes significado, seja no trabalho, no trânsito, no lar. Por se tratar de um processo que sofre interferência do nível de saúde, do conhecimento, da atenção, do estado emocional, a capacidade de percepção de risco das pessoas varia ao longo do tempo).

Portanto, em determinadas circunstâncias o perigo real pode ser diferente do risco que é percebido pelo indivíduo, favorecendo a ocorrência de acidentes devido à exposição descuidada, ou seja, o excesso de confiança da pessoa pode interferir na percepção de risco de indivíduos mais experientes, achando que pelo fato de que nunca aconteceu nada, o risco real foi exagerado Bley (2007).

Um dos objetivos deste grupo de questões também era saber se na percepção dos participantes, os EPI's disponibilizados para manusear os resíduos eram suficientes para evitar acidentes. De uma maneira geral, os trabalhadores entrevistados consideraram suficientes o material disponibilizado para manusear os resíduos sólidos. Ao relacionarmos esta questão, com a questão anterior, é possível que uma menor percepção da importância na utilização dos EPI's associados foi em função do tempo que o trabalhador tinha na organização.

Buscou-se avaliar também, o quanto os trabalhadores estavam cientes ou eram comunicados sobre as ocorrências de acidentes no hospital HP. Durante a observação participante, foi apresentado pela área de gestão o controle da quantidade de acidentes gerados com manuseio de resíduos da unidade. Porém, os trabalhadores entrevistados não tinham conhecimento das informações nele contidas, ainda que ficassem sabendo dos acidentes, evidenciando que havia pouca divulgação de dados relativos aos acidentes decorrentes do manuseio de resíduos e tal situação pode interferir na percepção de risco dos trabalhadores ocasionando uma negligência quanto a utilização correta dos EPI's. Contudo, em sua maioria, os trabalhadores consideraram suficientes os protocolos emergenciais existentes e que estes atendiam as necessidades em caso de acidentes.

Portanto, excesso de confiança, falta de conhecimento e o não conhecimento a respeito dos acidentes decorrentes do manuseio incorreto dos resíduos da unidade pode favorecer uma negligencia na utilização dos EPI's, conforme resultado também observado no trabalho de Pereira (2011).

Já a questão se os perigos associados ao manuseio dos resíduos eram informados e monitorados apresentou um resultado importante, pois os trabalhadores do nível operacional (que trabalhavam diretamente com os RSS) consideraram que os perigos não eram devidamente informados e controlados, evidenciando que os trabalhadores deste nível não tinham a total compreensão dos protocolos disponibilizados e a participação efetiva nas questões de gestão da área que são pertinentes à área operacional.

Por sua vez, as Questões Bloco D tiveram como objetivo identificar quais eram os pontos do gerenciamento que requeriam atenção, se o processo atual atendia as necessidades de acordo com a geração de resíduos e a percepção de risco dos trabalhadores quanto a sistemática definida (Tabela 3). 
Tabela 3 - Questões referentes ao gerenciamento dos RSS na unidade e a sua relação com a percepção de risco

\begin{tabular}{|c|c|c|}
\hline PERGUNTA & RESPOSTAS & CATEGORIA \\
\hline $\begin{array}{l}\text { Considera que a } \\
\text { estrutura física do } \\
\text { local } \\
\text { armazenamento de } \\
\text { resíduos é adequada } \\
\text { para a quantidade e } \\
\text { os riscos gerados? } \\
\text { Justifique. }\end{array}$ & $\begin{array}{l}\text { Adequado e bem localizado (Ana.); } \\
\text { Longe dos pontos de coleta e pequeno (Aux.); } \\
\text { Espaço pequeno e pouco iluminado (Aux.); } \\
\text { Pequeno, úmido e pouco iluminado (Aux.); } \\
\text { Local pequeno, porém, estruturalmente adequado } \\
\text { (Coord., Gr.); } \\
\text { Não, pouco espaço (Aux.); }\end{array}$ & $\begin{array}{l}\text { Espaço restrito, mas } \\
\text { adequado }\end{array}$ \\
\hline $\begin{array}{lr}\text { Os recipientes } & \text { são } \\
\text { identificados } & \text { de } \\
\text { acordo com } & \text { seu } \\
\text { grupo e } & \text { risco } \\
\text { associado? } & \text { Isso } \\
\text { ajuda no } & \text { nerenciamento dos } \\
\text { resíduos? Por quê? }\end{array}$ & $\begin{array}{l}\text { Não são respeitados, sempre misturam os resíduos } \\
\text { (Aux.); } \\
\text { Sim, mas os resíduos são misturados (Aux.); } \\
\text { Sim, facilita o manuseio (Aux.); } \\
\text { São identificados, mas muitas vezes, não são } \\
\text { respeitados (Aux.); } \\
\text { Sim, mas não ajuda, as pessoas misturam os resíduos } \\
\text { (Ana.); } \\
\text { São, porém os funcionários não respeitam (Coord., } \\
\text { Gr.)); }\end{array}$ & $\begin{array}{l}\text { Facilita, mas os resíduos } \\
\text { são misturados }\end{array}$ \\
\hline
\end{tabular}

Fonte: Elaborado pelo autor.

Do total de participantes, $90 \%$ dos trabalhadores consideraram inadequada a estrutura disponibilizada para armazenamento dos resíduos, sendo esta pequena e longe do ponto de coleta dos demais resíduos. E por meio da observação participante, também ficou evidente que a estrutura refletia a respostas dos trabalhadores entrevistados, sendo evidenciado durante a visitação, resíduos do lado de fora do local estabelecido devido à quantidade de resíduos gerados na unidade.

Bucando-se aprofundar a questão que buscava avaliar se havia na unidade um local específico para armazenamento dos resíduos. De uma forma geral, havia entre os trabalhadores o conhecimento a respeito do local específico para armazenamento de resíduos. Os trabalhadores que discordaram em relação a isso eram, na maioria, integrantes dos grupos que não realizavam atividades operacionais e consideravam a estrutura inapropriada em função da quantidade de resíduos gerados.

Neste sentido, avaliando se na percepção dos trabalhadores o local onde os resíduos eram armazenados poderiam contribuir para a ocorrência de acidentes ou contaminações, houve uma divisão nas respostas dadas, sendo que $42 \%$ dos trabalhadores concordaram em grande parte que o local era apropriado e não favoreceria a ocorrência de acidentes ou contaminação, enquanto $50 \%$ discordavam em grande parte.

Contudo, ao se analisar detalhadamente as respostas por grupo verificou-se que $42 \%$ atuavam no primeiro estágio, onde se realizava a coleta e armazenava-se no ponto de coleta um, que ficava localizado nos intermédios dos andares da organização. Por outro lado, $50 \%$ atuavam no segundo estágio, que coletava resíduos do estágio um e dispensava no ponto de armazenagem (local avaliado nesta questão). No Estágio 1 de coleta não há acúmulo de material descartado, portanto, estes trabalhadores não tendo contato com os demais Estágios 2 e 3, podem apresentar uma percepção de risco diferente dos trabalhadores dos demais estágios em relação à qualidade da infraestrutura diponível, distanciando a percepção de risco do perigo real.

Para Martins et al. (2015) muitos indivíduos que atuam em ambientes de trabalho permeados por diversos perigos potenciais para acidentes têm, na maioria das vezes, uma visão parcial dos riscos e 
das medidas de segurança necessárias ao seu processo de trabalho. Desconhecendo, inclusive, o processo como um todo. Essa invisibilidade (total ou parcial) pode favorecer a execução de ações e a adoção de condutas por parte dos trabalhadores que os predispõem à ocorrência de acidentes.

Desta forma, é possível que a resposta do grupo de $42 \%$ tenha sido em função de não terem contato direto com o estágio 2 de coleta dos resíduos. Não possuindo o conhecimento necessário da estrutura apropriada para armazenamento dos resíduos, a resposta fica subjetiva, pois uma vez que não há o acúmulo excessivo no ESTÁGIO 1 estima-se que toda a estrutura de armazenamento era apropriada.

Quanto a percepção dos trabalhadores se o descarte realizado nos postos de trabalho era feito de forma seletiva, controlando possíveis misturas. Do total de participantes, $75 \%$ dos trabalhadores discordaram que a coleta seletiva das áreas geradoras de resíduos era feita de forma correta. Os $25 \%$ que concordaram com esta questão foram os trabalhadores atuantes na área de gestão, desta forma, o processo executado pelos trabalhadores da área operacional é considerado eficaz pelos responsáveis pela gestão, contudo, é algo que não reflete exatamente a realidade segundo os trabalhadores da área operacional.

Todavia, houve consenso quanto a identificação dos recipientes, onde a resposta dos trabalhadores foi de que existia essa identificação e que esta auxiliava no momento do manuseio dos resíduos, porém, mesmo possuindo identificação visível para separação dos resíduos, os mesmos não eram respeitados no momento do descarte pelos que geravam tais resíduos (no geral, enfermeiros e médicos), ocorrendo assim, a mistura deste material. Pereira (2011) destaca a importância que a segregação de resíduos seja feita na fonte de geração, minimizando a quantidade de materiais potencialmente infecciosos que inevitavelmente atingirão o solo, contaminando, assim, o meio ambiente, e, por conseguinte, a população.

Portanto, estes dois fatores (estrutura inadequada e o descarte irregular) aparentaram ser pontos críticos que favoreciam possíveis acidentes e contaminações do ambiente no qual estavam expostos. Lembrando que a separação correta também é prevista pela Anvisa e CONAMA e quando realizada favorece o melhor manejo e descarte final para cada tipo de residuo, o que reduz custo e diminuiu a probabilidade de acidentes e contaminação ambiental (Brasil, 2007).

Outro ponto importante, era se os recipientes onde os resíduos eram descartados evitavam o contato direto com o corpo. Do total de participantes, $58 \%$ dos trabalhadores consideraram que os recipientes não evitavam o contato direto com o corpo, sendo propícios para possíveis vazamentos nos ambientes onde estavam localizados, bem como expondo os trabalhadores a possíveis riscos associados ao seu manuseio. O grupo que considerou uma possível adequação, foram os trabalhadores que não possuíam o contato direto com os resíduos, ou seja, trabalhadores de gestão e do terceiro estágio de manuseio.

Observou-se também a questão sobre se a periodicidade de coleta era suficiente em função da quantidade de resíduos gerados pelas áreas, os resultados obtidos apresentaram uma variação entre as respostas. Do total de participantes, $67 \%$, disseram que não e os outros $33 \%$ que disseram que sim eram os que faziam parte do grupo de gestão da área. Desta forma, ficou evidente que há uma diferenciação de percepção quanto a suficiência da periodicidade de coleta dos resíduos, sendo que a área mais afetada (a área de coleta) é submetida à uma condição de aceitação e execução do processo, mesmo de forma não condizente com a quantidade de resíduos gerados, proporcionando possíveis misturas e acidentes.

Por fim, foi avaliado se as capacitações fornecidas pela instituição foram suficientes para o manuseio correto dos resíduos. E $75 \%$ dos trabalhadores concordaram que estas foram suficientes.

O Bloco E buscou avaliar os protocolos que eram aplicados e sua utilização pelos envolvidos nas atividades, tanto operacionais, como de gestão da área. Os protocolos são de extrema importância, tendo em vista que é a estruturação documental de um processo e como o realizar. Neste sentido, 
não apenas a existência de tais protocolos foram verificadas, mas também se eram condizentes para utilização de acordo com o nível de aplicação. Neste contexto, verificou-se que a organização buscou estruturar seus protocolos de acordo com o que é estabelecido nas normativas vigentes, bem como verificou-se que a ISO 9001:2015 era utilizada como referência de gestão dessa unidade hospitalar. Foi avaliado também se os trabalhadores tinham conhecimento da existência destes protocolos, se estes auxiliavam no gerenciamento dos resíduos e se estavam disponíveis para consulta. De acordo com as respostas (e a observação participante), havia protocolos direcionados para o manuseio correto dos RSS. A estrutura descrita pela gestão da área foi desenvolvida e disponibilizada para consulta sempre que necessário como forma de suporte documentado do correto manuseio dos resíduos. De uma forma geral, os trabalhadores tinham conhecimento quanto aos mesmos.

Quanto à compreensão dos trabalhadores sobre os protocolos que foram instituídos, e levando em consideração a importância do item, que é determinante para a interpretação e utilização correta dos protocolos, foi verificado que $67 \%$ dos trabalhadores disseram compreender o material disponibilizado. Com este resultado, é possível presumir que não houve uma interação entre os grupos para validação dos itens e como foram abordados. Esta condição desfavorece a utilização dos protocolos, ocasionando possíveis desvios no processo uma vez que os trabalhadores operacionais tinham dificuldade em sua utilização e entendimento.

Buscou-se avaliar também se os protocolos disponíveis eram suficientes para o gerenciamento adequado dos resíduos existentes. Do total de participantes, $67 \%$ dos trabalhadores concordaram que os protocolos eram suficientes para o gerenciamento adequado dos resíduos. Analisando os $33 \%$ que discordaram com a questão, foi possível correlacionar a resposta com o tempo de trabalho na organização, pois possuem cinco anos ou mais, tendo como integrante deste grupo de respostas os trabalhadores de gestão da área. $O$ aprofundamento da questão levou a concluir que a área de gestão considera que os protocolos necessitam de atualizações constantes para que atendam às novas situações que surgem no decorrer da execução do processo de manuseio, por este motivo, consideram que indiferente do nível de maturidade que estejam, sempre haverá a necessidade de melhoria contínua daquilo que é executado no momento.

Por fim buscou-se avaliar se os protocolos necessitavam de adequações para melhor atender as necessidades de quem os utilizava. Em conformidade com a questão anterior e complementando a resposta, mesmo havendo os protocolos abrangendo os resíduos gerados, houve o consenso da equipe que há a necessidade de melhorar continuamente os protocolos para entendimento e aplicação de forma efetiva do correto manuseio dos resíduos.

Já no Bloco $\mathrm{F}$ buscou-se compreender quais os possíveis impactos ambientais dos RSS oriundos da organização e quais as contramedidas adotadas em função de ocorrências de contaminação e/ou vazamentos no ambiente onde estavam localizados os resíduos (Tabela 4).

Todos consideraram que a cadeia de manuseio podia evitar acidentes em função da disponibilização de protocolos e recursos existentes, mesmo não tendo um conhecimento mais específico de quais seriam estas ocorrências, tendo em vista de que não há evidências de tais incidentes, os mesmos julgaram coerente a estrutura atual.

O grupo de trabalhadores que atuavam na área de gestão, descreveram com detalhes quais eram as medidas adotadas em caso de acidentes ambientais, além das medidas atuais de proteção. Contudo, os trabalhadores do nível operacional não souberam responder. Desta forma, há uma diferença perceptível no conhecimento de tais medidas entre os dois grupos, podendo resultar em acidentes uma vez que os trabalhadores que manuseiam os resíduos em si desconhecem os procedimentos vinculados às ocorrências. 
Tabela 4 - Bloco $F$ referente às questões ambientais e sua relação com a percepção de risco

\begin{tabular}{|c|c|c|}
\hline PERGUNTA & RESPOSTAS & CATEGORIA \\
\hline $\begin{array}{l}\text { A cadeia de } \\
\text { manuseio } \\
\text { (conhecimento, } \\
\text { riscos, } \\
\text { gerenciamento e } \\
\text { protocolos) pode } \\
\text { evitar acidentes } \\
\text { ambientais? } \\
\text { Justifique }\end{array}$ & $\begin{array}{l}\text { Não sei responder, acho que sim } \\
\text { (Aux.); } \\
\text { Sim, a estrutura fornecida é boa } \\
\text { (Aux.); Não, nem todos seguem os } \\
\text { procedimentos (Aux.); } \\
\quad \text { Sim, pois a estrutura elaborada prevê } \\
\text { ações de contenção e prevenção (Ana., } \\
\text { Coord.); } \\
\text { Sim, contaminação do solo (Gr.); }\end{array}$ & $\begin{array}{l}\text { Estrutura boa, } \\
\text { mas sem conhecimento } \\
\text { de todos }\end{array}$ \\
\hline $\begin{array}{l}\text { Existem de } \\
\text { ações } \\
\text { contenção } \\
\text { definidas em caso } \\
\text { de acidentes } \\
\text { ambientais? Quais? }\end{array}$ & $\begin{array}{l}\text { Desconheço (Aux.); } \\
\text { Sim, tem resíduos e equipamentos de } \\
\text { contenção (Ana.); } \\
\text { Acionar o alarme do hospital (Aux.); } \\
\text { Sim, tem resíduos e equipamentos de } \\
\text { contenção (Coord., Gr.); }\end{array}$ & $\begin{array}{l}\text { Existe ações, mas } \\
\text { nem todos conhecem }\end{array}$ \\
\hline
\end{tabular}

Fonte: Elaborado pelo autor.

Segundo a percepção dos trabalhadores, no que diz respeito ao armazenamento final, houve o consenso da área que a estrutura fornecida era suficiente para evitar transbordos e derramamentos, porém, nos estágios intermediários de armazenamento que eram localizados nas áreas da unidade, ocorria transbordos constantes dos resíduos, pois em determinadas áreas o volume gerado é superior à capacidade de armazenamento.

As diferenças na percepção de risco em relação à estrutura físico do local de armazenamento dos RSS ficaram evidente nas respostas dadas, que variaram conforme a ocupação do participante dentro do processo gerenciamento dos RSS, conforme segue: Adequado e bem localizado (Analista); Longe dos pontos de coleta e pequeno (Aulixiar); Espaço pequeno e pouco iluminado (Aulixiar); Pequeno, úmido e pouco iluminado (Aulixiar); Local pequeno, porém, estruturalmente adequado (Coordenador Geral); Não, pouco espaço (Aulixiar).

Quanto a questão se os resíduos eram separados corretamente nos estágios de armazenamento. Os trabalhadores que atuavam em áreas de exames e procedimentos específicos não geravam grande volume de resíduos, desta forma, não ocorrendo transbordos e derramamentos, porém os trabalhadores que atuam nas áreas de UTI (Unidade de Tratamento Intensivo) e emergências acabavam sendo expostos à esta condição devido ao volume de atendimentos realizados.

Por fim, foi avaliado se na percepção dos trabalhadores havia a existência de vetores que proliferam a contaminação do ambiente nos locais de armazenamento. Segundo as respostas obtidas, nas áreas internas do hospital não foram identificadas a presença de vetores, somente nas áreas externas. Entretanto, o hospital possuía o controle de praga e vetores atualizados e em dia, desta forma, caberia avaliar a efetividade da prestação desse serviço.

\section{Discussão}

É possível entender a percepção de risco como instrumento tanto de avaliação quanto de gerenciamento de riscos ambientais e à saúde, pois, o desenvolvimento de uma percepção de risco mais próxima do perigo real, se constitui como uma variável importante a ser levada em consideração dentro de uma organização, facilitando a implementação de uma gestão eficaz da segurança, saúde e menor probabilidade de acidentes ou impactos ambientais (Bello, 2014). 
Os resultados obtidos neste trabalho evidenciaram que a percepção de risco, a partir da visão da gestão, não levava em consideração a experiência dos trabalhadores que estavam em contato direto com os RSS, onde toda a estrutura da área foi elaborada de forma a atender a requisitos normativos que muitas vezes não eram entendidos por quem de fato realizava o manuseio dos resíduos, aspecto que nos remete às questões de investigação propostas inicialmente.

Os blocos de questões elaborados e aplicados nos níveis de gestão e operacional revelaram que, na maioria dos casos, a interpretação era diferente entre estes níveis. O nível de gestão, tinha uma visão de atendimento normativo dos requisitos, enquanto a parte operacional, era sujeita a interpretação subjetiva dos trabalhadores, que em alguns casos, tinha pouco conhecimento ou entendimento, portanto, fundamentada muito mais em seus conhecimentos práticos, vivência, deduções e conversas com os demais colegas da equipe do que nas informações elaboradas e disponibilizadas pela organização.

Neste sentido, no trabalho realizado por Alves et al. (2016) também ficou evidente que a carência de informações ou a diferença de interpretação acerca do processo de gerenciamento dos RSS pode levar a um favorecimento de acidentes, evidenciando a importância para que a Educação Continuada seja reforçada como uma possibilidade para a capacitação dos profissionais que manejam esses resíduos, auxiliando na sensibilização e tornando-os cônscios das suas responsabilidades.

Contudo, para além da variável "conhecimento" a respeito da percepção de risco em relação aos perigos a que estes trabalhadores estavam expostos, foram outros fatores que tiveram mais impacto direto na percepção de risco a respeito dos RSS no presente estudo, como por exemplo o tempo que o trabalhador possuía manuseando os RSS. Este fator pareceu gerar confiança na execução do trabalho, fazendo com que os trabalhadores ficassem mais expostos aos perigos (Bello, 2014). Assim a familiaridade e a naturalidade exclui a preocupação com o perigo porque este virou normal, familiar, levando o trabalhador a minimizá-lo ou negá-lo (Sukhsohale et al. 2013).

Quanto ao gerenciamento dos RSS, constatou-se que existiam protocolos de descarte, manuseio, transporte e armazenamento, porém, não sendo atendidos em todos os níveis. Os limites de descarte dos resíduos nos setores não eram obedecidos, bem como a coleta seletiva dos mesmos, favorecendo assim o transbordo das embalagens e a mistura dos resíduos. Outro fator crítico foi a infraestrutura disponibilizada pela organização, que não suportava a quantidade de resíduos gerados.

Portanto, mesmo que de uma forma geral, os trabalhadores tivessem uma percepção de risco relativamente próxima ao perigo real, este estavam sujeitos à acidentes e contaminações. Este resultado se assemelha ao resultado obtido em um estudo conduzido por Ferreira \& Teixeira (2010), cujo objetivo foi analisar as práticas de gestão de resíduos de saúde em hospitais da região do Algarve, Portugal, indicando que a separação dos resíduos era a principal deficiência na prática de RSS expondo os trabalhadores a perigos, mesmo estes tendo a percepção de risco próxima ao perigo real.

Desta forma, constatou-se no presente estudo que os trabalhadores que atuavam diretamente e indiretamente no manuseio e gerenciamento de RSS, estavam sujeitos a riscos à saúde, além do perigo de contaminações ambientais. No contexto geral, a organização estabeleceu de forma muito objetiva a estrutura e a documentação de gestão dos resíduos, porém a provisão de tais recursos permearam somente 0 atendimento aos requisitos legais atribuídos à gestão de RSS, não levando em consideração o fator humano que executava as atividades. A gestão disponibilizava protocolos ligados ao manuseio de RSS como prioridade no exercício das suas funções, contudo deixavam de lado questões cruciais ligadas ao entendimento e desenvolvimento de ações preventivas relacionadas à percepção de risco dos trabalhadores operacionais. Resultados que mostram a importância de se fazer no Brasil, um amplo estudo de percepção de riscos associados a gestão dos RSS, conforme o trabalho de Cafure \& Graciolli (2015). 


\section{CONCLUSÕES}

No que tange os benefícios advindos do gerenciamento ambiental, constatou-se que o grupo de resíduos classificados na unidade hospitalar pesquisada exigiam atenção especial, bem como técnicas corretas de gerenciamento, pois, devido a sua toxicidade, são potencialmente poluentes e impactantes no meio ambiente e na saúde humana. A relevância da proposta deste trabalho está no fato de que as informações levantadas propiciarão uma melhor compreensão em torno do manuseio dos RSS nesta unidade hospitalar, bem como qual o papel da Percepção de Risco neste processo, evidenciando a necessidade de reciclagens periódicas e uma melhoria na comunicação de risco entre a gestão e os funcionários do nível operacional.

Ficou claro que a unidade hospitalar investigada não possuía um programa de gerenciamento adequado, bem como estrutura física para suportar os resíduos gerados, somando se ainda a esta problemática o insuficiente embasamento dos trabalhadores do grupo operacional relacionado aos RSS dadas às proporções e relevâncias das questões ambientais e percepção de risco envolvida em torno das diversas consequências decorrentes da gestão atual dos RSS. Além disso, a unidade necessitava ter uma estrutura e um ambiente físico adequado e estimular a interação entre os setores com ênfase na separação adequada dos RSS. Os resultados obtidos evidenciaram que mesmo os trabalhadores tendo uma percepção de risco relativamente próxima ao perigo real, este estavam sujeitos a acidentes e contaminações devido à infraestrutura disponibilizada pela organização.

Destaca-se a importância que em estudos futuros sejam incluídas outras categorias profissionais que integram a equipe nesta unidade, particularmente médicos enfermeiros, pois foi constatado que mesmo os recipientes para a coleta dos RSS receberem identificação adequada, a separação correta não era acatada no momento do descarte, ocorrendo assim, a mistura deste material.

Por fim, conforme destacado anteriormente, os resultados obtidos no presente estudo, bem como as reflexões acerca das incertezas, perigos e riscos quando contextualizados na área de saúde, por exemplo, podem subsidiar estratégias que objetivem estabelecer prioridades de políticas institucionais, particularmente no tocando aos RSS.

\section{REFERÊNCIAS}

ALENCAR, L.D. Gerenciamento dos resíduos de serviços de saúde de uma unidade hospitalar pública no município de Sousa-PB (Dissertação de mestrado). Centro de Tecnologia e Recursos Naturais, Universidade Federal de Campina Grande, Campina Grande, 2017. Disponível em: http://dspace.sti.ufcg.edu.br:8080/ispui/handle/riufcg/1930. Acesso em 16 dezembro de 2020.

ALVES, A.K.S.; ARAÚJO, A.A.; RIBEIRO, I.A.P.; DUARTE NETA, M.A.; LAGES, M.G.G.; RIBEIRO, R.O. Gestão dos resíduos de serviços de saúde: mitigação dos impactos sanitário e ambiental. Revista UNINGÁ, v.25,n.2, p.66-72, 2016.

AULETE. Dicionário digital da língua portuguesa. Disponível em: http://www.aulete.com.br. Acesso em 31 de outubro de 2020.

\section{BARDIN, L. Análise de conteúdo. São Paulo: Edições 70, 2011.}

BARROS, P. M. G. A.; MELO, D. C. P.; LINS, E. A. M.; SILVA, R. F. Percepção dos profissionais de saúde quanto a gestão dos resíduos de serviço de saúde. Revista Ibero Americana de Ciências Ambientais, v. 11, n. 1, p.201-210, 2020. https://doi.org/10.6008/CBPC2179-6858.2020.001.0019

BELO, M. S. S. P. Contribuições dos estudos de percepção de risco para a análise e o gerenciamento de exposições humanas a agrotóxicos: o caso de Lucas do Rio Verde, MT (Tese Doutorado). Escola Nacional de Saúde Pública Sergio Arouca, Rio de Janeiro, 2014.

BLEY, J. Z. Comportamento seguro: a psicologia da segurança no trabalho e a educação para a prevenção de doenças e acidentes $2^{a}$. ed, Vol. 1, Curitiba: Editora Sol, 2007.

BRASIL. Lei no 9.605, de 12 de fevereiro de 1998. Institui os Crimes Ambientais. Brasília: Diário Oficial da União, Seção 1.

BRASIL. Resolução RDC no 306, de 7 de setembro de 2007. Dispõe sobre o Regulamento Técnico para o gerenciamento de resíduos de serviços de saúde. Brasília: Diário Oficial da União, Seção 1. 
BRASIL. Lei ํㅜ 12.305, de 2 de agosto de 2010. Institui a Política Nacional de Resíduos Sólidos. Brasília: Diário Oficial da União, Seção 1.

BRASIL. Ministério do Desenvolvimento Regional. Secretaria Nacional de Saneamento - SNS. Sistema Nacional de Informações sobre Saneamento: Diagnóstico do Manejo de Resíduos Sólidos Urbanos - 2018, 2019. Brasília: NS/MDR.

CAFURE, V.A.; PATRIARCHA-GRACIOLLI, S.R. Os resíduos de serviço de saúde e seus impactos ambientais: uma revisão bibliográfica. Interações, v. 16, n. 2, p. 301-314, 2015. https://doi.org/10.1590/151870122015206

CAMARGO, Â. R.; MELO, I.B.N. A percepção profissional sobre o gerenciamento dos resíduos de serviços de saúde em unidades básicas e ambulatórios de saúde em um município da Região Metropolitana de Sorocaba, SP, Brasil, 2017. O Mundo da Saúde, v. 41, n. 4, p. 633-643, 2017. https://doi.org/10.15343/0104-7809.20174104633643

CONAMA. Resolução № 358, de 29 de abril de 2005. Dispõe sobre o tratamento e a disposição fi nal dos resíduos dos serviços de saúde e dá outras providências. Brasília: Diário Oficial da União, Seção 1.

CRESWELL, J. W. Projeto de Pesquisa: métodos qualitativo, quantitativo e misto (3. Ed). Porto Alegre: Artmed, 2010.

DENZIN, K., \& LINCOLN, Y. S. Handbook of qualitative research. Thousand Oaks: Sage publications. 2000.

FERRAREZE, M.V.G.; ANDRADE, D.; SILVA, M.F.I.; SANTOS, L.S.; FERREIRA, V. Gerenciamento de resíduos de serviços de saúde: avaliação de um centro de terapia intensiva. REME Rev. min. Enferm, v. 9, n. 2, p.133-139, 2007. Disponível em: < http://www.reme.org.br/artigo/detalhes/451>. Acesso em: 02 de março de 2021.1

FERREIRA, V.; TEIXEIRA, M.R. Healthcare waste management practices and risk perceptions: Findings from hospitals in the Algarve region, Portugal. Waste Management, v. 30, n. 12, p. 26572663, 2010. https://doi.org/10.1016/i.wasman.2010.07.012

GONÇALVES, E.M.N.; SANTOS, C.B. dos; BADARÓ, M.L. de S.; FARIA, V.A.; RODRIGUES, E.; MENDES, M.E.; SUMITA, N.M. Modelo de implantação de plano de gerenciamento de resíduos no laboratório clínico. Jornal Brasileiro de Patologia e Medicina Laboratorial, v. 47, n. 3, p. 249-255, 2011. https://doi.org/10.1590/S1676-24442011000300008

HOUAISS, A. Dicionário eletrônico Houaiss da língua portuguesa. São Paulo: Objetiva, 2002.

ITO, M.H. Resíduos volumosos no município de São Paulo: gerenciamento e valorização, Rev. Bras. Gest. Urbana, v. 11, n. 1, p.1-15, 2019. https://doi.org/10.1590/2175-3369.011.e20180117

KARKI, S.; NIRAULA, S.R.; YADAY, D.K.; CHAKRAVARTTY, A. Risk perception towards healthcare waste among community people in Kathmandu, Nepal. Plos One, v. 15, n. 3, p. 1-9, 2020. https://doi.org/10.1371/journal.pone.0230960

KLEIN, F.B.; GONÇALVES-DIAS, S.L.F.; JAYO, M. Gestão de resíduos sólidos urbanos nos municípios da Bacia Hidrográfica do Alto Tietê: uma análise sobre o uso de TIC no acesso à informação governamental, Rev. Bras. Gest. Urbana, v. 10, n. 1, p.140-153, 2019. https://doi.org/10.1590/2175-3369.010.001.a010

KOLLURU, R. Risk Assessment and Management: a Unified Approach. In: Kolluru, R.; Bartell, S.; Pitblado, R.; Stricoff, S. Risk Assessment and Management Handbook: for Environmental, Health and Safety Professionals. Writings on cities p. 1.3-1.4, 1996. Massachusetts: McGraw Hill.

LENT, R. Cem bilhões de neurônios? conceitos fundamentais de neurociencia. 2 ed., Vol. 1. São Paulo: Atheneu, 2010.

LIMA, M.L. Terramotos, Amor e Outras Coisas Perigosas: uma Abordagem Psicossociológica da Percepção de Risco. 1 ed., Vol. 1, 2003. Lisboa: Livros Horizonte.

LIN, J.; MILLS, A. Measuring the occupational health and safety performance of construction companies in Australia. Facilities, v. 19, n. 3-4, p. 131-138, 2001. https://doi.org/10.1108/02632770110381676 
MARCHI, C. M. D. F. Novas perspectivas na gestão do saneamento: apresentação de um modelo de destinação final de resíduos sólidos urbanos. Revista Brasileira de Gestão Urbana, v. 7, n. 1, p. 91 105, 2015. https://doi.org/10.1590/2175-3369.007.001.AO06

MARTINS, C.L.; ECHEVARRÍA-GUANILO, M.E.; SILVEIRA, D.T.; GONZALES, R.I.C.; DAL PAI, D. Percepção de risco sob a perspectiva de Trabalhadores com queimaduras. Texto \& Contexto Enfermagem, v. 24, n.4, 2015.

MENDES, A. P. A percepção ambiental dos resíduos de serviço de saúde - RSS da equipe de enfermagem de um hospital filantrópico de Araraquara - SP. Dissertação de Mestrado em Desenvolvimento Regional e Meio Ambiente. Centro Universitário de Araraquara UNIARA, SP, 2005.

NAVARRO, A.F. A. Percepção dos Riscos e sua influência na redução dos acidentes de trabalho. R. Bras. Risco e Seg., v. 6, n. 11, p. 35-66, 2010. Disponível em: < www.rbrs.com.br > Acesso em 27 de outubro de 2020.

PEREIRA, S. S. Gestão de resíduos de serviço de saúde e percepção ambiental: estudos de casos em unidades de saúde de Campina Grande/PB. Hygeia. Revista Brasileira de Geografia Médica e da Saúde, v. 7, n. 2, p. 106-126, 2011. Disponível em: < www.seer.ufu.br > Acesso em 30 de outubro de 2020

POFFO, I. R. F. Percepção de risco e comportamento da comunidade de acidentes ambientais em áreas portuárias de Santos e de São Sebastião (Pós-doutorado). Pontificia Universidade Católica, PUC/SP, 2011.

PORTELLA, M.O., RIBEIRO, J.C.J. Aterros sanitários: aspectos gerais e destino final dos residuos. Revista Direito Ambiental e sociedade, v. 4, n. 1, p. 115-134, 2014. Disponível em: < www.ucs.br/etc/revistas/index.php/direitoambiental/article/view/3687/2110 > Acesso em 29 de outubro de 2020.

RAMOS, Y. S.; ARAÚJO NETTO, F. B.; PESSOA, C.E.Q. Vulnerabilidade no manejo dos resíduos de serviço de saúde de João Pessoa (PB, Brasil). Ciências \& Saúde Coletiva, v. 6, n. 8, p. 3553-3560, 2011. https://doi.org/10.1590/S1413-81232011000900023

RODRIGUES, N. A.; SANTOS, E. F.; DIONE, G.I; GUIMARÃES, W.; SILVA, J. M.; PINHEIRO, T. M. M. Gerenciamento de resíduos de serviços de saúde na Universidade Federal de Minas Gerais: percepção de risco no ICB e no Campus Saúde, São Paulo. Rev Med Minas Gerais, v. 26, n.8, p. 194-199, 2016. Doi 10.5935/2238-3182.20160073

SANDERS, M.S.; MCCORMICK, E. J. Human Error, Accidents, and Safety. $7^{a}$ ed., Vol. 1, 1993. New York: McGraw-Hill.

SCHUELER, A.S.; KZURE, H.; RACCA, G.B. Como estão os resíduos urbanos nas favelas cariocas? Rev. Bras. Gest. Urbana, v. 10, n. 1, p.213-230, 2018. https://doi.org/10.1590/2175$\underline{3369.010 .001 .0015}$

SCHEIN, E. H. Organizational culture and leadership. $2^{\text {a }}$ ed. San Francisco: Jossey-Bassa 1992.

SILVA, E.J.; LIMA, M.G.; MARXIALE, M.H.P. O conceito de risco e os seus efeitos simbólicos nos acidentes com instrumentos perfurocortantes. Rev Bras Enferm, v. 65, n. 5, p. 1-21, 2012. Disponível em: < http://www.seer.ufu.br/index.php/hygeia/article/view/17011 > Acesso em 26 de novembro de 2020. https://doi.org/10.1590/S0034-71672012000500014

SILVA, C.L.; FUGII, G.M.; SANTOUO, A.H. Proposta de um modelo de avaliação das ações do poder público municipal perante as políticas de gestão de resíduos sólidos urbanos no Brasil: um estudo aplicado ao município de Curitiba. Rev. Bras. Gest. Urbana, v. 9, n. 2, p.276-292, 2017. https://doi.org/10.1590/2175-3369.009.002.ao09

SLOVIC, P. Perception of risk. Science, v. 236, n. 4799, p. 280-285, 1987. https://doi.org/10.1126/science.3563507 
SMITH, P.J. A percepção como uma relação: uma análise do conceito comum de percepção.

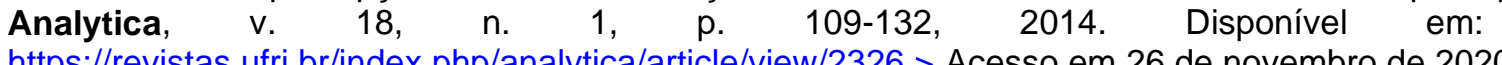
https://revistas.ufri.br/index.php/analytica/article/view/2326 > Acesso em 26 de novembro de 2020.

STEHLING, M.C., CUNHA, L.M., LOUREDO, L.M., CAMARGO, C.G., HADDAD, J.P.A, SILVA, I.J. Gestão de resíduos com risco biológico e perfurocortantes:conhecimento de estudantes de graduação das áreas Biológicas e da Saúde da Universidade Federal de Minas Gerais. REME, v. 17, n. 2, p. 594-600. Doi 10.5935/1415-2762.20130044.

SUKHSOHALE, N. D.; SAWANT, P. R.; THAKRE, S. S.; KHAMGAONKAR, M.B.; AGRAWAL, S. B. Effect of exposure to organophosphate pesticides in the children of agricultural workers in rural India. Riper Pdic Bulletin, v. 23, n. 1, 2013. Disponível em < https://docplayer.net/7449156-Riper-pdicbulletin-ispor-india-andhra-pradesh-chapter-newsletter.html > Acesso em 06 de dezembro de 2020. https://doi.org/10.29387/ms.2013.1.3.62-68

VIEIRA, C. R.; ROCHA, J.H.A.; LAFAYETTE, K.P.V.; SILVA, D.M. Análise dos fatores de influência e diagnóstico da gestão dos resíduos da construção civil (RCC) nos canteiros de obra da cidade do Recife-PE. Rev. Bras. Gest. Urbana, v. 11, n. 1, p.1-13, 2019. https://doi.org/10.1590/2175$\underline{3369.011 . e 20180176}$

ZAMONER, M. Modelo para avaliação de planos de gerenciamento de resíduos de serviços de saúde (PGRSS) para Secretarias Municipais da Saúde e/ou do Meio Ambiente. Cien Saúde Colet., v.13, n.6, p.1945-52, 2008. Disponível em: $<$ http://bases.bireme.br/cgibin/ wxislind.exe/iah/online/?IsisScript=iah/iah.xis\&base=-MEDLINE\&lang=p>. Acesso em: 16 dez.2013. https://doi.org/10.1590/S1413-81232008000600030 